\title{
Homens e o Movimento Feminista no Brasil: rastros em fragmentos de memória*
}

\author{
Mariana Azevedo** \\ Benedito Medrado*** \\ Jorge Lyra****
}

\begin{abstract}
Resumo
Este artigo apresenta argumentos que buscam favorecer reflexões, valorizar a produção de narrativas pouco visibilizadas na história do feminismo brasileiro, estimulando debates sobre os limites e possibilidades do reconhecimento dos homens como sujeitos na luta feminista por justiça social com equidade de gênero, tendo por base resultados produzidos no contexto de pesquisa de pósgraduação.
\end{abstract}

Palavras-chave: Feminismo, Homens, Gênero, Masculinidades.

* Recebido em 24 de setembro de 2015, aceito em 25 de setembro de 2018.

** Doutoranda do Programa de Pós-Graduação em Ciências Sociais da Unicamp e membro da coordenação colegiada do Instituto Papai. marianaazevedo2@gmail.com / https://orcid.org/0000-0003-4389-0237

*** Docente dos cursos de graduação e pós-graduação em Psicologia da Universidade Federal de Pernambuco (UFPE), Recife, Brasil; um dos fundadores da Organização Não Governamental (ONG) Instituto Papai. beneditomedrado@gmail.com / https://orcid.org/0000-0002-1085-5024

**** Docente dos cursos de graduação e de pós-graduação em Psicologia da Universidade Federal de Pernambuco (UFPE), Recife, Brasil; um dos fundadores da Organização Não Governamental (ONG), Instituto Papai. jorglyra@gmail.com / https://orcid.org/0000-0002-5381-2059 
cadernos pagu (54), 2018:e185414 Homens no Movimento Feminista no Brasil: rastros em fragmentos de memória

Men in the Feminist Movement in Brazil: Tracks in Fragments of Memory

\begin{abstract}
This article presents arguments that encourage reflections on and valorize the production of narratives that have had little visibility in the history of Brazilian feminism, stimulating debates about the limits and possibilities for recognition of men as subjects in the feminist struggle for social justice with gender equity, based on the results of graduate research projects.
\end{abstract}

Keywords: Feminism, Men, Gender, Masculinities. 


\section{Introdução}

Este artigo foi produzido a partir das discussões sobre os resultados de pesquisa de mestrado ${ }^{1} e$ apresenta argumentos que buscam favorecer reflexões, valorizar a produção de outras narrativas e estimular debates sobre os limites e possibilidades do reconhecimento dos homens como sujeitos na luta feminista por justiça social com equidade de gênero.

$\mathrm{O}$ debate acerca da relação entre homens e movimento feminista pode parecer, à primeira vista, algo novo. Essa primeira impressão se justifica, por um lado, pelo fato de ainda ser um número relativamente pequeno de homens que tem vindo a público, de forma organizada ou não, reivindicar uma identidade política feminista. Por outro lado, temos observado nos últimos anos um crescimento do debate público em torno dessa questão, seja em encontros acadêmicos, da militância, em atos públicos ou em meios virtuais de comunicação como sites, blogs e redes sociais.

Neste artigo, pretendemos produzir um exercício de inspiração genealógica acerca da emergência dessa questão a partir de dois campos discursivos e de ação política que se complementam e influenciam mutuamente: a militância feminista $e$ a produção acadêmica sobre gênero e masculinidades que tem se debruçado sobre o debate acerca dos homens enquanto sujeitos políticos do feminismo.

Assim, apresentamos inicialmente um breve histórico que procura apresentar as diversas formas de apoio e participação dos homens nas ações e reivindicações feministas desde o marco das lutas sufragistas no Brasil, até os dias atuais. Em um segundo momento, percorremos a trilha das teorias feministas e de gênero na tentativa de analisar a possibilidade de emergência do homem como sujeito político do feminismo, a partir de algumas teorias que informam esse movimento social.

1 Para trabalho completo ver: "Homens Feministas: a emergência de um sujeito político entre fronteiras contingentes", de autoria de Mariana Azevedo (2012). 


\section{Da nostalgia confortante à esperança que mobiliza: situando uma posição sobre memória}

"Féminisme amnésique" é o título de um provocativo texto, publicado recentemente $(09 / 05 / 2014)$ no jornal francês Libération, pelo filósofo Paul Beatriz Preciado ${ }^{2}$, um dos principais expoentes da aclamada, e nem sempre bem empregada, Teoria Queer.

Nesse curto texto, o autor nos alerta para o fato de que palavras como "homossexualidade", "transexualidade", "gênero" $e$ inclusive "feminismo" não foram termos que surgiram originalmente dentro dos movimentos sociais, mas sim no discurso médico, patologicista, dos últimos dois séculos. O surgimento desses termos está, segundo o autor, intimamente relacionado com as práticas de dominação "somatopolítica" na modernidade, cuja linguagem passou a se articular em torno de aparatos de verificação técnico-científica, em substituição à verificação teológica característica do século XVII.

A partir de eventos históricos do final do século XIX e começo do século XX, este autor argumenta que "os primeiros feministas foram homens" (2014:1). Para sustentar esse argumento, ele faz referência à primeira enunciação do termo "feminismo" que foi produzida por um homem (médico) para falar sobre a feminização como sintoma que a tuberculose poderia produzir em alguns homens. Posteriormente, ele fala sobre o feminismo como certa denúncia sobre homens que, pela proximidade com o movimento político das sufragistas, acabavam por feminizar-se. Detalhando essas narrativas, ele diz que:

A noção de feminismo foi inventada em 1871 pelo jovem
médico francês Ferdinand-Valerè Fanneau de La Cour em
sua tese de doutorado "Do feminismo e do infantilismo nos
tuberculosos". Segundo a hipótese científica de Ferdinand-

${ }^{2}$ Uma das referencias sobre as teorias queer é a filósofa Beatriz Preciado que fez uma transição e hoje em dia se nomeia como Paul/ Beatriz Preciado, e em nosso texto a partir deste momento iremos referenciá-la pelo masculino. 
Valerè Fanneau de La Cour, o "feminismo" era uma patologia que afetava os homens tuberculosos, produzindo, como sintoma secundário, uma "feminização" do corpo masculino.

$\mathrm{O}$ varão tuberculoso, disse Ferdinand-Valerè Fanneau de La Cour, "tem os cabelos e as sobrancelhas finas, cílios longos e finos como das mulheres; a pele é branca, fina $e$ flexível, a panícula adiposa subcutânea muito desenvolvida $e$, por conseguinte, os contornos fingem uma suavidade considerável, enquanto as articulações e os músculos conjugam seus esforços para fornecer flexibilidade aos movimentos, esse não-sei-o-quê ondulante e gracioso que próprio da gata e da mulher (...) Os órgãos genitais são reconhecidos pela sua pequenez". Feminizado, sem "potência de geração e faculdade de concepção", o homem tuberculoso perde sua condição de cidadão viril e torna-se um agente comunicador que deve ser colocado sob a tutela da medicina pública (2014:8, tradução nossa). ${ }^{3}$

Em sua argumentação, Preciado nos informa que Alexandre Dumas-Filho retomou essa noção médica de feminismo, para se referir pejorativamente aos homens solidários ao movimento de

3 No original: "La notion de féminisme fut inventée en 1871 par le jeune médecin français Ferdinand-Valère Fanneau de La Cour dans sa thèse doctorale "Du féminisme et de l'infantilisme chez les tuberculeux". Selon l'hypothèse scientifique de Ferdinand-Valère Fanneau de La Cour, le "féminisme» était une pathologie qui affectait les hommes tuberculeux, produisant, comme un symptôme secondaire, une "féminisation" du corps masculin. Le mâle tuberculeux, dit Ferdinand-Valère Fanneau de La Cour, "a les cheveux et les sourcils fins, les cils longs et fins comme ceux des femmes; la peau est blanche, fine et souple, le panicule adipeux sous-cutané très développé, et par conséquent les contours affectent une mollesse remarquable, en même temps que les articulations et les muscles combinent leur action pour donner aux mouvements cette souplesse, ce je-ne-sais-quoi d'ondulant et de gracieux qui est le propre de la chatte et de la femme. (...) Les organes génitaux sont remarquables par leur petitesse.» Féminisé, sans "puissance de génération et faculté de conception", l'homme tuberculeux perd sa condition de citoyen viril et devient un agent contaminateur qui doit être placé sous la tutelle de la médecine publique”. 
mulheres que lutavam pela igualdade política e pelo direito ao voto, conhecido como movimento "sufragista". Segundo DumasFilho, esses homens aliados das sufragistas corriam o risco de sofrer do mesmo mal da feminização a que padeciam os varões tuberculosos. A esse movimento de aliança, ele chamava "feminismo".

A pesquisadora feminista portuguesa Anne Cova já havia narrado essa história, muito antes de Preciado, em 1998, e talvez com maior precisão. Segundo ela, o termo "feminismo" na verdade surge, conforme abusivamente referido em diversos dicionários, a partir de textos do utopista Charles Fourier (17721837), por volta de 1830.

É verdade que inúmeras feministas francesas da Terceira República francesa viam em Charles Fourier um precursor do feminismo. Outros eram os que, juntamente com ele, disputavam esse título: o Marquês de Condorcet (17431794) e Léon Richer (1824-1911) [considerados] personalidades emblemáticas para as feministas. Este último é o fundador, em 1882, da Ligue française pour le droit des femmes, com a finalidade de obter a igualdade entre os dois sexos. O Marquês de Condorcet, filósofo do Século das Luzes e da Déclaration des droits de l'homme et du citoyen, é um fervoroso partidário do voto das mulheres. É considerado por muitas feministas da Terceira República Francesa "o pai do feminismo". Um mês antes do deflagrar da I Guerra Mundial, a 5 de Julho de 1914, teve lugar, junto à estátua de Condorcet, em Paris, uma grande manifestação sufragista feminista, que reuniu seis mil pessoas, marcando a consagração do movimento. A escolha simbólica da estátua de Condorcet para local de encontro não foi ao acaso e reflete o desejo das feministas de honrar uma personalidade consensual e de expor publicamente a sua aspiração a um movimento misto (Cova, 1998:8).

Contudo, Cova (1998) também atribui o nascimento do termo "feminismo", na sua acepção moderna, à Alexandre 
Dumas-filho, filho do famoso escritor Alexandre Dumas, que empregou em 1872 a palavra feminismo como adjetivo pejorativo para designar os aliados das sufragistas, numa obra intitulada "L'Homme-femme". A referência à tese de 1971, do médico francês Ferdinand-Valerè Fanneau de La Cour, que teria inspirado Dumas-Filho, tal qual referido por Preciado, aparece, segundo Covas (1998), já na obra da investigadora e filósofa Geneviève Fraisse, de $1984 .^{4}$

O termo "feminismo" surge, assim, segundo Cova (1898), na França, entre as décadas de 1870-1880, difundindo-se em outros países nos anos subsequentes. Em 1882, Hubertine Auclert, reconhecida como a primeira sufragista, proclamou-se publicamente feminista e em 1892, o termo "feminista" já fora empregado num congresso organizado por mulheres.

Mas, Cova (1998) é bastante cuidadosa ao informar que antes dos movimentos feministas se organizarem como tal, já havia atos feministas isolados.
É assim, que, embora o termo não fizesse parte da linguagem corrente, Olympe de Gouges, publica, em 1791, uma Déclaration des droits de la femme et de la citoyenne sobre o modelo da Déclaration des droits de l'homme et du citoyen. Além desse gesto isolado de feminismo, não existe qualquer outro texto doutrinal fundador, que constituísse uma referência incontornável para as feministas (1998:9).

Essa autora conclui que, como consequência, "o feminismo oferece, desde os seus princípios, múltiplas facetas" (1998:10).

Concordamos com Cova e reconhecemos o esforço de Preciado por denunciar a tirania de algumas políticas identitárias que fixam sujeitos e forjam fronteiras muitas vezes intransponíveis. De fato, é necessário abrir alianças com todos os sujeitos que resistam à normalização e à exclusão, "aos efeminados da história", como refere a autora.

${ }^{4}$ Ver também Fraisse (1989). 
Porém, discordamos de seu argumento de que as palavras estejam tão presas assim ao seu mito de origem. Afinal, as operações históricas sobre as quais se organizam as linguagens, enquanto práticas sociais, não exterminam a performatividade, ou seja, a capacidade que as palavras têm de produzir efeitos, de fabricar coisas, nem sempre desejáveis ou previstas em sua enunciação original.

Ao afirmar que o profeta e o político buscam sacralizar as palavras, "ocultando sua historicidade", Preciado defende que à filosofia e à poesia cabe a "tarefa profana de restituir as palavras sacralizadas ao uso cotidiano" (2014:01). Nesse sentido, ele mesmo nos convida a ir além da sacralização do passado.

Porém, talvez Preciado tenha caído na armadilha que Eduardo Galeano chamaria de "memória morta", em oposição à "memória viva", que, segundo ele, não nasceu para âncora, mas ao contrário, tem vocação de catapulta, pois, segundo ele:

Cuando está de veras viva, la memoria no contempla la historia, sino que invita a hacerla. Más que en los museos, donde la pobre se aburre, la memoria está en el aire que respiramos. Ella, desde el aire, nos respira. Es contradictoria, como nosotros. Nunca está quieta. Con nosotros, cambia. A medida que van pasando los años, y los años nos van cambiando, va cambiando también nuestro recuerdo de lo vivido, lo visto y lo escuchado. Y a menudo ocurre que ponemos en la memoria lo que en ella queremos encontrar, como suele hacer la policía con los allanamientos. La nostalgia, por ejemplo, que tan gustosa es, y que tan generosamente nos brinda el calorcito de su refugio, es también tramposa: ¿Cuantas veces preferimos el pasado que inventamos al presente que nos desafía y al futuro que nos da miedo? (...)

"La memoria no reniega de la nostalgia, pero prefiere la esperanza, su peligro, su intemperie. Creyeron los griegos que la memoria es hermana del tiempo y de la mar, y no se equivocaron" (1997:01). 
Neste artigo, buscamos adotar essa versão mais potente $e$ rica de memória. $\mathrm{E}$, nesse sentido, reconhecemos que o "feminismo" como ação política está distante da acepção patológica do termo original e do "protagonismo" de homens que lhe deram o nome. O próprio termo "queer", caro a Preciado apropriado recentemente pelo chamado movimento pósidentitário para se referir a uma leitura da sexualidade para além das dicotomias homem-mulher, hetero-homo, masculino-feminino - tem uma narrativa semelhante. Ao adotar a ofensa ${ }^{5}$ como afirmação política, esse movimento que se definiu como "queer" produziu uma transgressão simbólica, deslocando o sentido original (de xingamento) para uma acepção que se configura como afirmação de uma posição política no campo da sexualidade. Como reconhece a própria Preciado, as sufragistas se reapropriam dessa "denominação patológica" e a transformaram em um "lugar de identificação e ação política" (2014:01), não de modo simples ou conformado, mas profundamente subversivo. Consideramos que, há muito, o termo "feminismo" é empregado em seu sentido mais subversivo do que monolítico, patologizante ou regulador, obviamente não sem reservas.

Além disso, como nos adverte Cova (1998), o emprego do termo "feminismo" esconde um mosaico de referências diversas, muito distantes do conjunto homogêneo que muitas vezes é forjado como referência seja por aqueles/as que buscam definir territórios e, consequentemente, promover violências sobre quem tenta migrar por entre fronteiras; seja por aqueles/as que se dizem críticos/as do feminismo "desde fora". Como conclui a autora, a "aparente comunhão de ideologias sob a bandeira do feminismo esconde a variedade de feminismos". Por isso, segundo ela, "é necessário, também, não esquecer os homens feministas, mesmo que sejam minoritários entre as feministas" (1998:9).

${ }^{5}$ De modo simplificado, o termo "queer" é usado nos Estados Unidos de modo pejorativo para se referir a pessoas que não se enquadram em padrões heteronormativos. 


\section{Um campo político: homens e movimento feminista no Brasil}

É importante ressaltar que a relação entre homens $e$ movimento feminista brasileiro remonta às origens desse movimento social, mesmo que de forma pontual em seu início. Fazendo uso da clássica periodização que estabelece a chamada primeira onda do feminismo como a fase em que predominaram as lutas sufragistas, no final do século XIX; e a segunda onda como aquela que se inicia com os movimentos de contracultura na década de 1960, podemos notar como essa relação vem se tornando cada vez mais complexa, engendrando questões para a teoria e a prática feminista.

Em seu trabalho sobre as lutas pelos direitos da mulher no Brasil, entre as décadas de 1850 e 1940, June Hahner (2003) traz algumas referências sobre como homens participaram e apoiaram ações nesse primeiro momento do feminismo brasileiro. $\mathrm{Na}$ segunda metade do século XIX, as primeiras movimentações se resumiam a um seleto grupo de mulheres da elite brasileira que, a partir de sua participação no movimento abolicionista, passaram a editar jornais que exigiam a emancipação feminina.

O primeiro deles foi $O$ Jornal das Senhoras ${ }^{6}$, editado no Rio de Janeiro e cujo lançamento ocorreu em janeiro de 1852 (Harner, 2003; Teles, 1993). Em seu relato, Hahner coloca que vários dos artigos publicados no jornal foram assinados por homens. Nesse momento também teve importância a luta pelo direito à educação - até então, às meninas só era permitido o ensino de primeiro grau - tendo vários homens se manifestado publicamente em sua defesa. Foi o caso de um grupo de brasileiros que estudavam em Nova Iorque e publicaram um artigo em outro jornal feminista da época, O Domingo ${ }^{7}$ (Hahner, 2003).

${ }^{6}$ O Jornal Das Senhoras foi editado de 1852 a 1856 no Rio de Janeiro. Sua primeira editora foi Joana Paulo Manso de Noronha, que em seu primeiro editorial expôs seus objetivos: "Trabalhar pelo melhoramento social e para a emancipação da mulher" (Harner, 2003:84).

7 O jornal O Domingo foi editado no Rio de Janeiro de 1873 a 1875. De propriedade de Violante Ximenes de Bivar e Velasco, que já tinha sido editora do 
Hahner afirma que, nas décadas de 20 e 30 do século XX, apesar de algumas mudanças, ainda eram poucas as mulheres com acesso à educação e que conseguiam adentrar em campos profissionais elitistas, como o direito e a medicina. Foram essas mulheres de elite que lideraram a campanha sufragista, que contou ainda com a participação de donas de casa de classe média e professoras.

É interessante perceber como, nessa época, boa parte dos discursos públicos pró-direitos da mulher combinavam elementos progressistas e outros que apenas atualizavam a posição de subordinação das mulheres, vendo o acesso à educação, por exemplo, como uma forma de melhorar o desempenho feminino nas atividades do lar, entendido como seu lugar por excelência na sociedade. Nesse sentido, o apoio de homens às causas feministas muitas vezes também ocorria de forma a preservar os lugares de homens e das mulheres na sociedade. June Harner por exemplo afirma que:

\begin{abstract}
mesmo em Teresina, capital do Piauí, um dos mais pobres do país, alguns homens viam a "causa do feminismo" como "nobre e simpática" (...) Mas o "radicalismo feminista", que buscava a desorganização da sociedade somente ofendia os homens (...) (Harner, 2003:250).
\end{abstract}

Em um momento de emergente organização das mulheres, realizou-se, em 1922, o primeiro Congresso Feminino pela Federação Brasileira pelo Progresso Feminino (FBPF). A fim de obter maior divulgação e legitimidade para o evento, foram convidados alguns homens estadistas, sendo que um deles presidiu a sessão final do congresso, que teve como tema a defesa do sufrágio feminino. Esse primeiro momento do movimento feminista no Brasil teve como marco final o ano de 1934, quando

Jornal das Senhoras, após o afastamento de Joana Noronha. O jornal cessou suas atividades devido às dificuldades financeiras com a morte de sua proprietária e mantenedora (Harner, 2003). 
o direito ao voto foi conquistado na Constituição promulgada naquele ano.

Da década de 1930 até 1975, ano considerado como marco da segunda onda do feminismo brasileiro, as mulheres continuam fundando jornais, associações, realizando congressos $e$ assembleias. Contudo, no contexto de ditadura militar (19641985), as mulheres se incorporaram à luta pela democracia em um movimento mais amplo de esquerda, do qual faziam parte, ainda, partidos políticos, alas progressistas da Igreja Católica e de igrejas do protestantismo tradicional e movimentos sociais rurais $e$ urbanos (Teles, 1993). Mariza Corrêa (2001) chama a atenção ainda para o intenso diálogo entre as feministas e o movimento homossexual (denominação à época), que de diferentes formas também contribuiu nas discussões relativas a gênero $e$ sexualidade.

Essa composição com diferentes grupos, entidades $e$ instituições em defesa da democracia se dá numa aparente unidade, mas não sem conflitos entre os partícipes. Evidentemente, tais conflitos e tensões estavam presentes também entre movimentos feministas e outros setores, bem como entre os diferentes grupos de mulheres. São amplamente relatados os embates entre as consideradas mulheres de partido em torno da prioridade da luta mais geral - leia-se luta de classes e pela democracia - $e$ as feministas voltadas às "demandas das mulheres".

Havia conflito também entre mulheres das classes populares, ligadas aos movimentos urbanos e/ou pastorais, $e$ aquelas oriundas das classes médias, que igualmente tinham prioridades diferentes sobre as demandas mais urgentes para $\mathrm{o}$ movimento de mulheres. Incluem-se, ainda, nos meandros desses confrontos, as concessões políticas relativas à sexualidade $e$ ao aborto em particular, para que fosse conservada a então estratégica aliança com a Igreja Católica (Corrêa, 2001; Costa, 1988; Rago, 2003; Sarti, 1998, 2004; Teles, 1993).

Simultaneamente às iniciativas de articulação apontadas acima, o ano de 1975 foi declarado, pela Organização das Nações 
Unidas (ONU) como o Ano Internacional da Mulher e como ano de início da década da mulher. Esse ato teve grande importância, particularmente para o Brasil, pois sob uma ditadura militar, as mulheres tiveram respaldo para continuar $e$ ampliar sua organização política. No mesmo ano, além do Movimento Feminino pela Anistia, foram fundadas duas importantes organizações, o Centro da Mulher Brasileira no Rio de Janeiro e o Centro de Desenvolvimento da Mulher Brasileira em São Paulo. Foi também em 1975 que se iniciaram as comemorações do dia 08 de março em vários estados do país (Corrêa, 2001; Costa, 1988; Rago, 2003; Sarti, 1988; Teles, 1993).

Em julho daquele ano, o Centro de Informações das Nações Unidas no Brasil e a Associação Brasileira de Imprensa (ABI) organizaram, no Rio de Janeiro, a Semana da Pesquisa sobre o Papel e o Comportamento da Mulher Brasileira, considerada como o primeiro encontro da segunda onda feminista brasileira. Nesse evento, verificamos mais uma vez a participação de homens, que, segundo Mariza Figueiredo (2008), foi estimulada pelas próprias organizadoras. Elas convidaram, por exemplo, Celso Furtado para o encerramento da semana.

Nesse período, a edição de jornais continua sendo uma importante estratégia de ação do movimento feminista. Em um contexto de ditadura militar, surge o que alguns chamarão de imprensa alternativa ou democrática. Além de jornais feministas, como o Brasil Mulher e o Nós Mulheres, esse período foi marcado por diversas outras publicações tais como: $O$ Pasquim, Opinião, Em tempo, Movimento, Lampião, Versus, De Fato, dentre outros (Leite, 2003).

Em 1975, no Paraná, é lançado o primeiro número do Brasil Mulher. ${ }^{8}$ Já em São Paulo, em 1976 começa a ser editado o jornal

8 O jornal Brasil Mulher - publicado de 1975 a 1980 pela Sociedade Brasil Mulher - e Nós Mulheres - publicado de 1976 a 1978 pela Associação de Mulheres - eram formados majoritariamente por militantes de esquerda $e$ serviam como veículo para divulgação das atividades da associação como também para abordar questões que não eram veiculados na grande mídia (Leite, 2012). 
feminista Nós Mulheres, que em pouco tempo se desarticulou. Algumas das integrantes deste jornal continuaram a se reunir na Fundação Carlos Chagas, que já era um importante polo de pesquisas feministas. Com o apoio da Fundação, foi editado de 1981 a 1988 o jornal feminista Mulherio ${ }^{9}$ (Corrêa, 2001; Rago, 2003). É em seu primeiro número que encontramos uma nota intitulada Homens em ação. Ela apresenta um relato sobre a criação de um grupo de homens a partir de um famoso caso de violência contra a mulher.

$\mathrm{Na}$ esteira das manifestações contra o assassinato de Eliane de Grammont por Lindomar Castilho, uma importante iniciativa foi tomada em São Paulo: a criação do "Grupo masculino de apoio à luta das mulheres". Participam do grupo escritores, jornalistas $e$ intelectuais de formação variada, interessados em "trabalhar juntos por uma sociedade na qual mulheres e homens sejam igualmente livres". O grupo divulgou um "manifesto contra a barbárie", no qual expressam "repúdio frontal à desabusada invocação do tabu da 'honra masculina' para justificar" os assassinatos de mulheres, "considerando que cabe à mulher o mesmo direito que ao homem de tomar decisões sobre suas vidas. Entendemos que as relações afetivas homemmulher são também relações de poder. A morte do outro, o homicídio do outro não lava nem suja a honra de ninguém. A honra da pessoa reside nela própria e não no outro" (Mulherio, 1981:04).

9 O jornal Mulherio surgiu como uma proposta de pesquisadoras da Fundação Carlos Chagas em criar um instrumento que pudesse sistematizar e fazer circular informações sobre o então chamado campo de estudos sobre a condição feminina no Brasil. O jornal foi publicado de 1981 a 1988, quando passou a se chamar: Nexo, Feminismo, Informação e Cultura e teve ainda dois números publicados. 


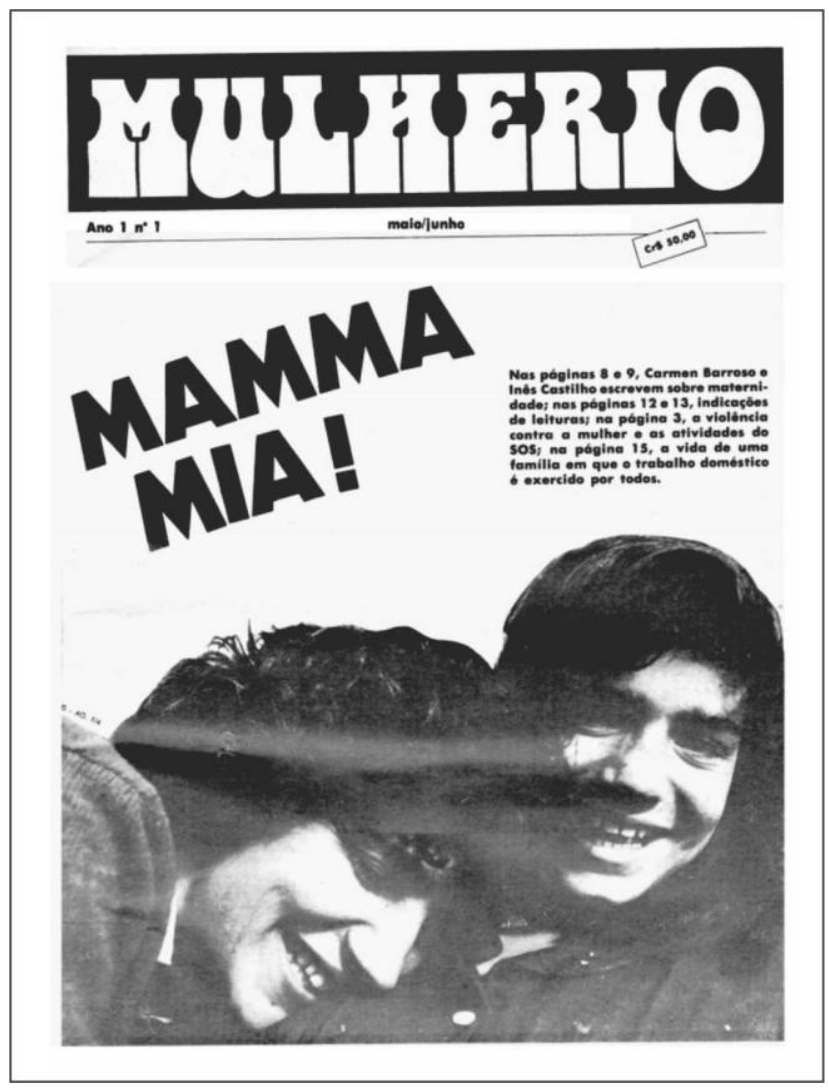

Fonte: Fundação Carlos Chagas

www.fcc.org.br/conteudosespeciais/mulherio/arquivo/I 1 1981menor.pdf.

Essa nota é a primeira e única referência a esse grupo, que parece ter sido o primeiro grupo de homens organizado em prol de causas feministas em nosso país. Até então, temos apenas o registro de apoios individuais $e$ esporádicos às ações $e$ reivindicações feministas.

É também nas páginas do jornal Mulherio que é travado um polêmico debate sobre a posição dos homens em relação ao movimento feminista. Essa polêmica se inicia com um artigo, do então professor universitário Aloísio Mercadante, sobre a 
conquista do direito à licença paternidade pelos professores da Pontifícia Universidade Católica de São Paulo (Mercadante, 1982).

No artigo intitulado "Ser macho é cinza", Mercadante coloca seu espanto frente ao silêncio dos homens em relação à conquista de um direito que os beneficia diretamente, em contraposição à vibrante reação pública das mulheres. Segundo ele, isso se deve ao fato de que a vontade de repensar os termos da relação homem-mulher tenha sido historicamente uma preocupação feminista/feminina, já que são as mulheres as diretamente prejudicadas pelo machismo. Mercadante passa então a discorrer sobre como o machismo também traz prejuízos à vida dos homens, especialmente nas questões emocionais $e$ afetivas $e$ conclui argumentando que: "Pensar a possibilidade de uma relação homem/mulher mais criativa não é uma tarefa exclusiva do feminismo, é uma tarefa nossa e inadiável" (Mercadante, 1982:3).

O artigo é denso por formular uma linha de argumentação diferente do simples apoio público às ações feministas. Preocupase em expor as consequências negativas do machismo para a vida dos homens e, por conseguinte, a necessidade de se organizarem em prol de relações igualitárias, beneficiando homens e mulheres.

Duas edições depois, a mesma revista publica uma carta do leitor Lúcio Teles, um brasileiro residente no Canadá, que integra o grupo "Homens de Toronto Contra o Sexismo". Na carta, Lúcio enfatiza o impacto do artigo de Aloísio Mercadante, mas questiona seu argumento central de que ser macho seria ser cinza, ressaltando os privilégios masculinos em relação à mulher. Afirma ainda que seu grupo em Toronto reconhece que cabe às mulheres a luta contra a opressão que sofrem e que a questão de como os homens devem participar consiste numa das mais controvertidas dentro do grupo (Teles, 1982).

Dando continuidade ao debate sobre como incorporar os homens à luta feminista, é publicado, nas páginas seguintes às da carta de Lúcio, um artigo da educadora Maria Malta Campos com o polêmico título "Feminismo e separatismo" (Campos, 1982). Nele, a educadora discute a necessidade de o movimento 
feminista abandonar o que ela afirma ser uma estratégia separatista em relação aos homens. Segundo a autora, ao se organizarem, os grupos minoritários passam por uma fase inicial de introspecção em busca de sua identidade. Entretanto, durante o processo de luta por transformação, os embates também se transformam, alianças são feitas e desfeitas. Ainda segundo Maria Malta Campos, o movimento feminista já teria, naquela época, atingido um grau de maturidade em que o separatismo em relação aos homens não faria mais sentido, pois esse não é um objetivo do movimento enquanto tal. O que teria sido um fator importante para despertá-lo de uma nova consciência, revelar-se-ia, agora, como um fator de estagnação (Campos, 1982).

A polêmica se encerra, ao menos nas páginas do jornal, em seu número seguinte, quando é publicado mais um artigo sobre a questão, dessa vez da escritora Danda Prado. O artigo não possui título, mas é aberto com uma ilustrativa charge em que um homem está na porta de uma pequena casa onde se lê a inscrição: "Clube da Luluzinha", e que tem afixado na porta um cartaz escrito que "Homem não entra". 


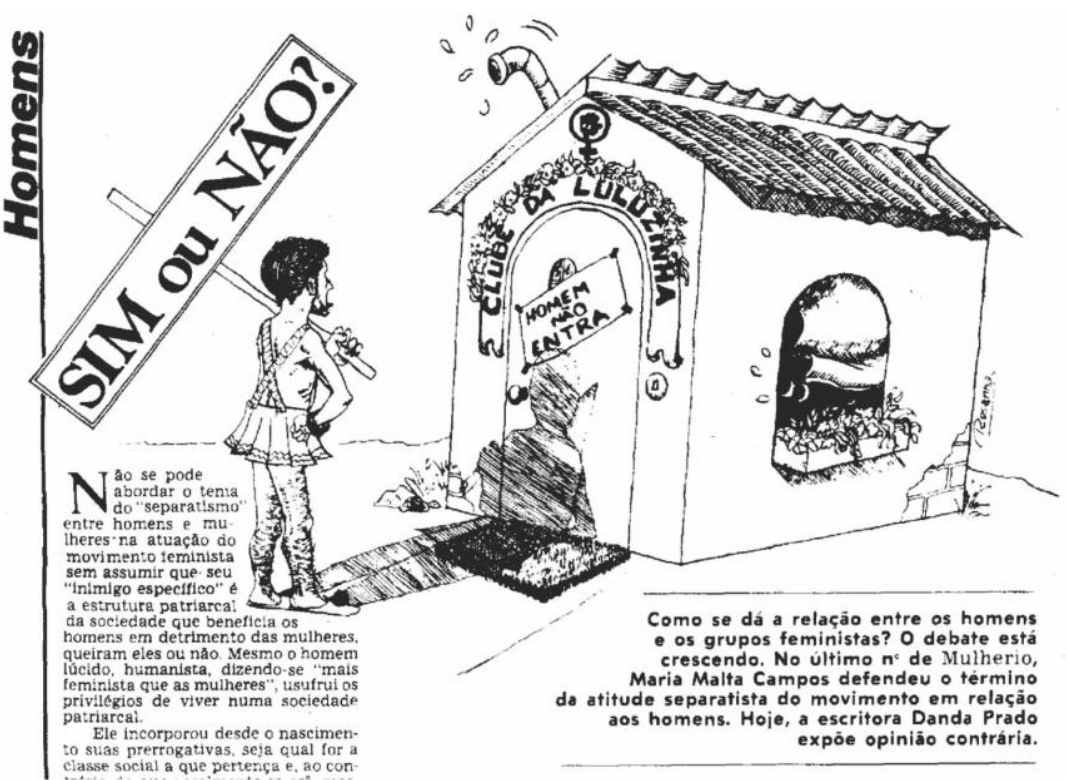

Fonte: Fundação Carlos Chagas www.fcc.org.br/conteudosespeciais/mulherio/arquivo/II 10 1982menor.pdf.

Nesse artigo, a autora se opõe abertamente à posição de Maria Malta Campos, afirmando que no Brasil ou em qualquer outro país o feminismo está longe de constituir um novo $\mathrm{Eu}$, e que a incorporação de homens às lutas não depende das mulheres, mas de que os homens se questionem e lutem pela transformação dos privilégios que usufruem. Ao colocar a necessidade de autoorganização dos homens, Danda Prado cita o exemplo do grupo de Toronto, referido na já citada carta do leitor Lúcio Teles, publicada na edição número 9 do jornal Mulherio (Prado, 1982).

Ainda sobre a aproximação de homens aos espaços de organização do movimento feminista, em artigo sobre a inserção dos homens nos estudos de gênero, Karen Giffin (2005) relata que durante a década de 1960, especialmente no âmbito universitário e em outros espaços da classe média, havia homens interessados 
em participar das discussões. Contudo, essa participação foi vetada pelas mulheres. Estratégia, segundo a autora, necessária, ao menos num primeiro momento, diante das experiências das mulheres com a "dominação masculina".

$\mathrm{Na}$ década de 1990, o chamado processo de institucionalização do movimento feminista, que se iniciara ainda na década de 1970, já está consolidado. São inúmeras as organizações não governamentais e grupos que se articulam em redes e fóruns e organizam encontros nacionais e internacionais. A inserção do feminismo na academia, também iniciada nos anos 1970 com os estudos sobre mulheres ganha nova força na década de 1990, com o que é tido, por muitas autoras, como um dos maiores avanços teóricos feministas: os estudos de gênero (Galvão, 2008).

É também na década de 1990 que começam a se popularizar, no Brasil, os estudos sobre masculinidades e são fundados alguns grupos e organizações não governamentais voltadas ao trabalho com homens. Nesse contexto, temos a fundação, em Recife, no ano de 1997, da organização não governamental feminista Instituto Papai que, como indica a sua missão institucional, tem como objetivo principal
contribuir para o fortalecimento das ações da sociedade civil que visam à igualdade de direitos entre homens $e$ mulheres, promovendo a formulação e o monitoramento de políticas públicas orientadas pela perspectiva feminista e de gênero (Instituto Papai, 2011).

Apesar de termos a fundação de algumas organizações voltadas ao trabalho com homens, a partir do viés de gênero, o Instituto Papai é uma das únicas que se apresenta como feminista.

A etnografia de Aline Bonetti (2007) sobre o campo político feminista da cidade de Recife aborda brevemente a relação entre o Instituto Papai e o campo feminista da cidade. Falando das alteridades em disputa nesse campo, Bonetti menciona que um ponto de deslocamento de sentido, na oposição "nós versus elas", 
relaciona-se à identificação de um "nós" a favor dos homens e de gênero e de um "elas" feminista contra os homens. Essa diferenciação engendraria alianças e embates, como por exemplo, entre o Instituto Papai e o Fórum de Mulheres de Pernambuco (FMPE).

Segundo afirma Bonetti, o Instituto Papai enfrenta certo desconforto na sua participação no FMPE, o mais importante fórum de articulação feminista local (com repercussão latinoamericana), pelo fato de ter homens em seu foco de trabalho (Bonetti, 2007). O Instituto Papai não é a única organização mista que integra o Fórum, porém, apesar de ser composta por ativistas homens e mulheres, é a única que tem como foco de suas ações os homens e as masculinidades.

Em entrevista a Bonetti, um dos fundadores do Instituto Papai relembra o momento de ingresso da organização no FMPE. Esse episódio concretiza a polêmica sobre os limites $e$ possibilidades da relação entre homens e movimento feminista que vimos no acalorado debate que se deu nas páginas do extinto jornal Mulherio.

Em 2000, o Instituto Papai participou do Encontro Nacional Feminista ocorrido na Paraíba, com uma proposta de oficina sobre masculinidades e passou, a partir de então, a integrar o FMPE. Como homens não podiam participar do referido encontro, integrantes mulheres da organização tiveram que ministrar a oficina.

Posteriormente, a atuação da organização foi reconhecida pelo fórum e Karla Galvão (na época integrante da coordenação do Instituto Papai) chegou a compor a coordenação tríplice do fórum (biênio 2003-2005), junto com Ana Bosh (Grupo Loucas de Pedra Lilás) e Mônica Laranjeiras (Trupe Graúna). Na negociação para assumir esse lugar, ficou claro que a representação na rede não poderia ser substituída por outro integrante da instituição, a não ser que fosse uma mulher. A mesma exigência de "se fazer representar por uma mulher" permanece válida e condição sine qua non para a participação do Instituto Papai no FMPE até os dias de hoje (Bonetti, 2007). 
Mais recentemente, Karla Galvão (2008), em sua tese de doutorado sobre o campo feminista brasileiro, debruça-se sobre a Conferência Estadual de Santa Catarina e a Conferência Nacional de Políticas para as Mulheres de 2004, realizada em Brasília, com o propósito de compreender a dinâmica da relação entre movimento feminista e a esfera governamental. Ao relatar os principais acontecimentos da Conferência de Santa Catarina, a autora apresenta como se desdobrou a questão sobre a participação de delegados homens nas etapas estadual e nacional da conferência.

Por terem sido eleitos como delegados nas pré-conferências regionais, havia dois homens participando daquela etapa estadual. Galvão narra que durante a leitura do regimento interno da conferência esta situação gerou um mal estar entre alguns segmentos de mulheres que foi se ampliando, culminando com a inclusão de uma cláusula no regimento que vetava a eleição de delegados homens para a etapa nacional. Nesse momento a autora traz as considerações de uma das participantes acerca dessa questão:

E cita um homem que vem participando das lutas do movimento feminista como exemplo de homens que são parceiros. Estes teriam legitimidade de participar do processo, porém, representarem as mulheres, ocupando a posição de delegado era bem diferente. "Eles já nos representam demais..." Comenta sobre os espaços de poder, nos quais mais homens que mulheres estão presentes (Galvão, 2008:166).

Aqui, a questão da representação demarca os limites $e$ possibilidades da relação entre homens e movimento feminista. Como afirma a participante da conferência, parece ser possível pensar em homens participando de diversas formas dos espaços de atuação do movimento feminista, desde que isso não abra a possibilidade de eles ocuparem espaços de poder como representantes das demandas do movimento. Situação semelhante ocorre na Conferência Nacional de Política para as Mulheres a 
partir da participação de dois delegados homens dos estados de Minas Gerais e Rio Grande do Norte.

$\mathrm{Na}$ etapa nacional, essa situação engendrou uma discussão sobre o que seriam políticas de gênero e políticas para as mulheres. Havia um entendimento de que existia uma diferença entre políticas voltadas especificamente para os direitos das mulheres $e$ as políticas de gênero, que poderiam beneficiar também os homens. Karla Galvão aponta como esse episódio é revelador de como a relação entre sexo e gênero é um elemento forte da formulação de ações e políticas feministas, sendo que o "feminismo" aí aparece como sinônimo de "mulher" (Galvão, 2008).

A partir dessa breve retrospectiva da relação entre homens e movimento feminista, desde meados do século XIX em nosso país, podemos observar como essa relação vem se complexificando. Inicialmente como ações isoladas de apoio, temos hoje homens que se definem como aliados do feminismo ou pró-feministas, uma forma de identificação que preserva certa zona de conforto na relação com o movimento feminista, assim como com grupos de homens que reivindicam uma identidade política feminista.

\section{Sobre homens e movimento feminista}

A partir da década de 1990 encontramos um conjunto de publicações, especialmente em língua inglesa, que tiveram como foco o debate sobre a relação entre homens e feminismo. Uma das mais importantes é a coletânea "Men doing feminism" (1998), organizada por Thomas Digby, que recolhe vários ensaios acerca do tema. Michael Kimmel, cujo ensaio "Who's afraid of men doing feminism?" foi publicado na coletânea organizada por Digby, publica já em 1992, juntamente com Mosmillet, o livro "Against the tide: Pro-feminist men in the United States". Nele, demonstra como homens partidários do feminismo têm sido uma corrente minoritária no cenário político americano nos últimos dois séculos (Kaufman, 1994). Também nos Estados Unidos encontramos Michael Kaufman (1994), que dedica parte de seu livro Theorizing 
Masculinities à discussão sobre homes e feminismo. Na Europa temos ainda Welzer-Lang, que dedica parte de seu livro "Les hommes et le masculin" (2004) ao que ele denomina homens prófeministas.

É no âmbito desses estudos que surge o termo "homens pró-feministas", utilizado por autores que consideram que pelo fato de os homens não terem necessariamente acesso às experiências de opressão como as mulheres, não podem se declarar feministas, mas sim apoiadores do movimento (Kaufman, 1994; Kimmel, 1998; Kimmel \& Mosmiller, 1992; Welzer-Lang, 2004 apud Matias, 2008). Em sua dissertação sobre as narrativas de homens feministas portugueses, Matias (2008) traz uma definição de homens pró-feminista:

Homens, investigadores ou não, que procuram refletir sobre a sua atividade (militante, intelectual ou social) numa perspectiva critica do androcentrismo, próxima do pensamento feminista; homens que, pela sua atividade, revelam a dominação masculina e participam na sua erradicação de forma efetiva; os homens pró-feministas são assim homens que apoiam as mulheres na sua luta por igualdade e liberdade (Matias, 2008:14).

Apesar de esses homens se engajarem no projeto feminista, o termo pró-feminista é cunhado mantendo uma lógica binária, que se apoia no critério último da diferenciação sexual e que coloca o feminismo como algo de mulheres e o antifeminismo ou não feminismo como algo de homens. Se nos dispusermos a refletir na contramão dessa lógica, poderemos associar o não feminismo ao sexismo ou machismo, considerando as experiências dos homens como base para o compromisso com o feminismo, dando maior atenção às práticas dos homens $e$ não recorrendo a lógicas essencialistas.

Sobre as diferentes experiências de opressão vividas por homens e mulheres dentro de uma ordem desigual de gênero, alguns autores indicam que o reconhecimento dos custos $e$ sofrimentos causados aos homens pelo sexismo ou machismo 
pode ser uma forma, não de transformá-los em vítimas ou de desresponsabilizá-los por seus atos - especialmente nos casos de homens que cometeram violência -, mas de sensibilizá-los frente ao projeto feminista (Medrado; Lyra, 2008).

É nesse bojo que Michael Kaufman (1994) traça sua análise do surgimento do que ele chama de uma posição pró-feminista entre os homens. Em uma atitude analítica e ao mesmo tempo militante, o autor afirma que a tomada de consciência das experiências contraditórias de poder entre os homens é a base para que se engajem no feminismo. Segundo o autor, nas sociedades patriarcais, existe na vida dos homens uma contraditória combinação entre poder, privilégios, dor e falta de poder.
(...) la manera como hemos armado esse mundo de poder causa dolor, aislamiento y alienación tanto a las mujeres como a los hombres. Esto no significa equiparar el dolor de los hombres con las formas sistemáticas de opresión sobre las mujeres, solamente quiere decir que el poder de los hombres en el mundo -cuando estamos descansando en la casa o caminando por las calles, dedicados al trabajo o marchando a través de la historia- tiene su costo para nosotros. Esta combinación de poder y dolor es la historia secreta de la vida de los hombres, la experiencia contradictoria del poder entre ellos (Kaufman, 1994:1).

Essa compreensão passa pelo entendimento do patriarcado como um sistema contraditório de poder. Isso porque: 1) as formas de masculinidade que ele engendra são prejudiciais não só para as mulheres, mas também para os homens; e 2) porque esse não é apenas um sistema de dominação dos homens sobre as mulheres, mas também de hierarquias entre as diferentes formas de masculinidade (Kaufman, 1994).

Essas experiências contraditórias de poder entre os homens funcionam, segundo Kaufman, como um sistema de recompensas, em que as experiências de dor dos homens são escamoteadas pelo poder e pelos privilégios que gozam. $\mathrm{O}$ feminismo tem nesse 
sentido um papel importante, pois ao alterar essa balança entre dor e poder coloca em questão as fontes de privilégios e poder masculinos (Kaufman, 1994).

Para esse autor, um movimento de homens tem que tomar como ponto de partida o poder e os privilégios masculinos, mas também o reconhecimento dos custos desse poder e desses privilégios para os homens. Nesse sentido, advoga por um movimento que supere as limitações de duas vertentes atuais do movimento dos homens, que têm tratado isoladamente os dois aspectos da vida dos homens que são cruciais à sua análise: a tendência mito-poética, com sua ênfase na dor dos homens, e o movimento pró-feminista que tem enfocado as expressões de poder e privilégios masculinos. "Al hacerlo así, ignoran no sólo el significado de toda la experiencia masculina en uma sociedad dominada por los hombres, sino también la relación crucial entre el poder y el dolor de los hombres" (Kaufman, 1994:16).

Mesmo afirmando sua filiação à vertente pró-feminista, Kaufman não deixa de problematizar esse termo que, segundo o autor, sugeriria que o patriarcado não é um problema específico para os homens. Seguindo seu argumento da necessidade de se incluir uma análise do impacto de uma sociedade dominada por homens sobre eles mesmos, Kaufman afirma que o projeto passa então a não ser apenas pró-feminista - no sentido de homens apoiando as mulheres e questionando o poder deles sobre as mulheres - mas antisexista, antipatriarcal $e$ antimasculinista (Kaufman, 1994).

Na mesa redonda Homens e Feminismo, realizada durante o III Colóquio Internacional de Estudos sobre Homens $e$ Masculinidades, em 2008, na Colômbia, o antropólogo Fernando Hernandez tenta responder a questão de se os homens podem ser feministas ou não a partir do questionamento de qual é o sujeito político do feminismo. Para isso recupera algumas ideias chave do feminismo que tocam diretamente nessa questão e que já foi nosso objeto de discussão (Hernández, 2008).

A primeira e fundamental ideia se ancora no conceito de gênero para afirmar que uma mulher não é uma evidência 
biologia, mas sim uma construção social. A consequência disso para o debate acerca do sujeito do feminismo é que, como afirma o autor,

\begin{abstract}
Si la mujer es una construcción social, algo que se llega a ser, hay otros sujetos que podrían ser susceptibles de ocupar tanto ese lugar social como político - en el caso de las travestis por ejemplo. Pero, ¿dónde están los hombres en esta historia? (Hernández, 2008:3).
\end{abstract}

Outra ideia que cerca esse debate é o entendimento de que ocupar um lugar na ordem de gênero não faz (nem impossibilita) de maneira imediata um sujeito político. Trazendo a reflexão de Patrícia Hill Collins sobre o feminismo negro, Hernández (2008) toca em uma questão importante: a de que se deve renunciar a uma visão materialista e determinista, que suponha um tipo de experiência e consciência automática pelo fato de ser mulher. Mas também evitar os riscos do idealismo, adotando uma posição crítica que tenha em vista uma história e a localização social particular dos sujeitos (Hernández, 2008).

Nesse ponto, Hernández recupera a questão do lugar de enunciação para refletir sobre a determinação do sujeito político do feminismo. Seguindo o exemplo de Kaufman, Hernández assinala como os homens ocupam ao mesmo tempo um lugar de dominação e subordinação. Isso porque "1) un hombre es justamente eso: un hombre; y 2) los hombres no son solamente hombres" (Hernández, 2008:5). A primeira questão assinala que mesmo engajado nos ideais feministas, os homens continuam gozando de sua posição social dominante enquanto homens. Entretanto, sendo diversos entre si, os homens estão localizados nas mais distintas posições de poder. Assim, para o autor, uma das pistas para se compreender a identificação dos homens com o feminismo é de que em geral se tratam de homens que fazem parte de outras minorias, seja sexual, racial, de classe etc. (Hernández, 2008). 
Mesmo tendo em vista que o lugar ocupado pelos sujeitos na ordem social é fundamental para a construção de um movimento social, o autor questiona se é pertinente conformar um movimento a partir do sexo.

\begin{abstract}
Me pregunto entonces entre la diversidad de las mujeres cuáles serían las más aptas para encarnar a ese sujeto político ideal. (...) Creo que esta cuestión vale la pena ser explorada desde una posibilidad no necesariamente identitaria. Precisamente, esa cuestión identitaria esencialista de ser mujer natural y auténtica para ser mujer política, ha sido cuestionada por sujetas que se definen a sí mismas como antisexistas, antirracistas, anticlassistas, y no como mujeres, como negras e indígenas o como proletarias (Hernández, 2008:6).
\end{abstract}

Outros autores têm recorrido de forma diferente às experiências dos homens como forma de compreender seu engajamento no feminismo. Em seu trabalho sobre homens feministas de Portugal, Matias (2008) refere resultados de alguns trabalhos sobre o que chamam de "homens antisexistas". A conclusão da autora é que a maioria desses homens teve experiências de gênero não tradicionais em sua infância. Ela também refere que esses homens relatavam influência de pelo menos uma mulher feminista, em sua vida adulta, seja no âmbito de relações amorosas ou de amizade, o que, de algum modo, talvez configuraria contextos e experiências favoráveis a uma posição antisexista.

Em sua tese sobre masculinidades e violência de gênero, Elizabeth Etayo (2011) dedica parte de seu trabalho à investigação das narrativas de alguns homens feministas no Brasil a fim de estabelecer um contraponto com as narrativas dos homens autores de violência. De forma diversa das conclusões apresentadas por Christian (apud Matias, 2008), Etayo afirma que através dos depoimentos pode-se perceber que em sua infância, adolescência e juventude, esses homens tiveram uma socialização que 
os conduziria a um homem tradicional de valores patriarcais do que para o feminismo. Contudo, esses homens feministas optaram por outros caminhos, talvez por situações que até são alheias às suas próprias decisões (Etayo, 2011:112).

Em trabalho apresentado no último encontro Fazendo Gênero, em 2010, Karla Galvão e Marion Quadros discutem a relação entre os sujeitos do feminismo e demandas de novos sujeitos, em particular os homens. As autoras se colocam a tarefa de refletir sobre essa questão a partir de três pontos: 1) compreender como os homens surgiram como "aliados" do feminismo no Brasil; 2) localizar a participação dos homens no espaço doméstico e no cuidado com os filhos; e 3) entender os significados que a participação dos homens nessas duas instâncias tem para o feminismo (Galvão; Quadros, 2010).

Sobre a participação dos homens como aliados do feminismo no Brasil, as autoras recuperam a história do surgimento da segunda onda do feminismo brasileiro. Nesse momento histórico, o argumento em prol de espaços específicos para as mulheres se organiza a partir de dois pontos. $\mathrm{O}$ primeiro diz respeito ao entendimento de que a presença de homens significaria uma barreira para o processo de conscientização das mulheres, na medida em que representavam a "opressão em sua forma estrutural". Esse argumento é o que fundamenta a formação dos grupos de reflexão sobre a condição feminina, estratégia na época já muito utilizada na Europa e que chegou ao Brasil com as mulheres que retornavam do exílio político. $\mathrm{O}$ segundo ponto, que consolida o primeiro, mas traz também um aspecto conjuntural, diz respeito à inserção das mulheres na luta pela redemocratização, um espaço político em que os homens predominavam nos cargos de poder (Galvão; Quadros, 2010).

No tocante à participação dos homens na vida doméstica $e$ no cuidado com os filhos, as autoras apontam que, a partir da década de 1980, algumas feministas começaram a afirmar a necessidade de envolvimento dos homens na vida doméstica como forma de promover a igualdade entre homens e mulheres. 
Essa discussão sobre participação dos homens no lar e no cuidado com os filhos demonstra, segundo as autoras, o quão são minoria os homens que se incomodam com sua posição de dominação.

\begin{abstract}
Assim, esse incômodo parece mais localizado em grupos de homens específicos que fazem parte de minorias ou se identificam como alternativos. Ao estar lidando com homens específicos, incluindo-os não apenas nos estudos, mas também nas agendas de lutas, não requer um tratamento especifico da questão? Nesse caso estar lidando com homens específicos e que se identificam com o ideário feminista, pode contribuir para a busca de equidade? (Galvão; Quadros, 2010:6).
\end{abstract}

Sem negar a necessidade de tratar essa questão como específica, nos perguntamos: mulheres que se identificam como feministas ou que tenham atitudes igualitárias devem também ser entendidas como "específicas" ou "alternativas"? Ao fazer essa pergunta, abrimos possibilidades para pensar qual seria o fundamento da identificação com o ideário feminista, seja para homens ou mulheres, tentando abandonar qualquer argumento essencialista para uma possível resposta.

Podemos observar como a ideia de masculinidades subordinadas (ou alternativas), que tem suas origens nas formulações de Connel (1997) acerca da masculinidade hegemônica, exerce um papel importante nas reflexões que se indagam sobre a relação entre homens e feminismo. Nessas abordagens, parece ser necessário identificar outras posições de subordinação dos homens como fundamento para compreender essa relação.

Uma das principais críticas ao conceito de masculinidade hegemônica reside justamente em sua utilidade analítica. Se, por um lado, reconhecer que nenhum homem corresponde totalmente ao modelo hegemônico de masculinidade abre espaço para o entendimento de que todos os homens seriam em alguma medida subordinados, por outro, resta a crítica que afirma ser muito difícil postular a subordinação para as masculinidades, pois elas 
continuam sendo dominantes em relação às mulheres, como bem aponta o próprio Connel (1997) ao tocar na questão da cumplicidade frente à dominação patriarcal (Alves, 2005).

\section{O feminismo em novas rotas de coalizão: à guisa de (in)conclusões}

Consideramos que o debate acerca das diferentes posições de sujeito dos homens em relação ao feminismo não é simples $e$ remete aos diferentes usos do conceito de gênero no feminismo $e$ suas consequências para pensar seu sujeito político.

Como observa Linda Nicholson (2000), entre outras autoras, há pelo menos duas maneiras contraditórias de se referir ao gênero. Primeiramente, é usado em oposição ao sexo, referindose ao que é socialmente construído, quando sexo remete ao que é biologicamente determinado. $\mathrm{E}$, de outra forma, gênero tem sido usado "como referência a qualquer construção social que tenha a ver com a distinção masculino/feminino, incluindo as construções que separam corpos femininos e masculinos" (Nicholson, 2000:08).

Estas ambiguidades no uso do conceito de gênero remetem, segundo Nicholson (2000), às raízes dele, que tem origem na junção de duas ideias aparentemente contraditórias: a da base material da identidade e da construção social do caráter humano. Diferentes arranjos desses matizes engendram usos distintos do conceito de gênero como também formas diferentes de encarar o processo de constituição das identidades.

Para Nicholson (2000), a herança dessa concepção de gênero ainda permeia muitos escritos feministas e constitui a base daquilo que a autora vai chamar de "fundacionalismo biológico". O fundacionalismo é resultado da combinação de concepções oriundas do determinismo biológico e do construcionismo. Em meio ao século XX, ganhou força a ideia da construção social do caráter humano. Contudo, afirma a autora, muitos dos que aceitam essa ideia não rejeitam completamente a importância da biologia na formação desse caráter: "(...) veem o fisiológico como um 'dado' no qual as características específicas são 'sobrepostas', um 'dado' que fornece o lugar a partir do qual se estabelece o 
direcionamento das influências sociais" (Nicholson, 2000:10). Logo, para algumas proposições feministas, o sexo permanece funcionando como esse lugar que direciona as inscrições do gênero. Daí que surge a analogia da autora do corpo como um cabide, em que diferentes artefatos culturais são pendurados.

A vantagem de uma noção como essa é que ela permite sustentar que certas constantes biológicas são responsáveis por certas constantes sociais, sem ter que abrir mão da possibilidade de transformação destas últimas. O fundacionalismo permite ainda pensar as diferenças entre as mulheres ao mesmo tempo que mantém uma base sólida (o sexo) para pensar a unidade entre as mulheres (Nicholson, 2000; Mariano, 2005).

Ainda assim, essa forma de pensar a diferença revela-se igualmente falsa, pois não prevê ou não oferece ferramentas suficientes para pensar as quebras e fissuras nesse sistema de correspondências. Como, por exemplo, a respeito das pessoas que nascem com genitália masculina e se consideram mulheres ou até mesmo a possibilidade de existência das próprias feministas (Nicholson, 2000).

De fato, o próprio feminismo só foi possível, pelo menos em parte, como consequência de uma tendência cultural geral de algumas sociedades de base europeia a desassociar de certa forma biologia do caráter. Um dos pontos fracos de um feminismo baseado na diferença é que ele não pode explicar o fenômeno de tais sociedades terem produzidos feministas - pessoas que, devido à própria genitália, e por força do próprio argumento, deveriam ter-se tornado completamente femininas, mas cuja verdadeira habilidade política ou presença em instituições anteriormente dominadas por homens como a academia deve indicar uma certa dose de socialização masculina (Nicholson, 2000:23).

No lugar de uma posição fundacionalista a autora defende outro uso do conceito de gênero, em que o sexo não é encarado como pertencendo exclusivamente ao domínio da natureza, haja 
vista os corpos serem sempre observados a partir de uma interpretação social. Desse modo, não há mais critérios fixos para a definição do que seja "ser mulher". Contudo, como também afirma Stolke (2004), a questão não é de "jogar o bebê do sexo junto com água do banho", mas de perguntar em que circunstâncias históricas e quais as consequências da manutenção, e diria Nicholson, também das quebras e fissuras do dualismo sexual-biológico.

Dessa forma, propomo-nos a compreender a questão da reivindicação de uma identidade política feminista por parte de homens como uma expressão dessas possíveis descontinuidades entre corpos e prescrições de gênero, no sentido de que "tais critérios, [do que significa ser mulher] são considerados capazes de nos habilitar a distinguir o inimigo do aliado $e$ a fornecer a base para a o programa político do feminismo" (Nicholson, 2000:26) No lugar de uma política de identidade emerge uma abordagem antifundacionalista da política, que Judith Butler vai chamar de política de coalizões:

Uma coalizão aberta, portanto, afirmaria identidades alternativamente instituídas e abandonadas, segundo as propostas em curso; tratar-se-á de uma assembleia que permita múltiplas convergências e divergências, sem obediência a um telos normativo definidor (Butler, 2003:37).

Nesse sentido, a emergência dos homens como sujeito político do feminismo pode ser compreendida como uma expressão das possíveis descontinuidades entre corpos $e$ prescrições de gênero e como uma possibilidade ampliada de coalizão, numa perspectiva antifundacionalista do conceito de gênero. $\mathrm{O}$ envolvimento dos homens com o feminismo pode ser compreendido pelo fato de que, sendo "mulher" construção social, existem sujeitos que mesmo não correspondendo ao critério da diferença sexual podem vir a transitar também por esse lugar "social e político", deslocando certezas e abrindo outros horizontes de negociação, sem abster-se do conflito que certamente esse trânsito pode provocar ou intensificar. 
Refletindo sobre a política de coalizão, Linda Nicholson (2000) afirma que costumamos pensar nessa estratégia quando o movimento feminista se une em torno de alguma reivindicação com "outros" grupos com interesses claramente definidos. No entanto, por que não podemos pensar na política de coalizão como algo também interno ao movimento?

\section{Referências bibliográficas}

ALVES, Maria de Fátima. Masculinidade/s: considerações a partir da leitura crítica de alguns textos que focalizam os homens. Ártemis no3 João Pessoa, dez. 2005, pp.01-13.

AZEVEDO, Mariana. Homens Feministas: a emergência de um sujeito político entre fronteiras contingentes. Dissertação (Mestrado em Sociologia), Programa de Pós-Graduação em Sociologia, Universidade Federal de Pernambuco, Recife, 2012.

BUTLER, Judith. Problemas de gênero: feminismo e subversão da identidade. Rio de Janeiro, Civilização Brasileira, 2003.

CAMPOS, Maria Malta. Feminismo e separatismo. Mulherio, ano 2, n⿳9 9 , São Paulo, out. 1982, pp.3.

CONNEL, Robert. La organización social de la masculinidad. In: VALDES, T. OlavarRiA, J. (org.) Masculinidad/es: Poder y Crisis. Santiago, Ediciones de Las Mujeres, 1997, pp.31-48.

CORRÊA, Mariza. Do feminismo aos estudos de gênero no Brasil: um exemplo pessoal. cadernos pagu (16), Campinas,SP, Núcleo de Estudos de Gênero-Pagu/Unicamp, 2001, pp.13-30.

CostA, Albertina. O. É viável o feminismo nos trópicos? Resíduos de insatisfação - São Paulo, 1970. Cadernos de Pesquisa n66, São Paulo, 1988, pp.63-69.

Cova, Anne. O que é o feminismo? Uma abordagem histórica. Seminário "Movimento Feminista em Portugal'. Lisboa, UMAR, Dez. 1998

[http://umarfeminismos.org/images/stories/pdf/seminariomovfeminista. pdf - acesso em 06 jun. 2014]. 
cadernos pagu (54), 2018:e185414 Homens no Movimento Feminista no Brasil: rastros em fragmentos de memória

ETAYO, Elisabeth. Nem anjos, nem demônios: homens comuns. Narrativas sobre masculinidades e violência de gênero. Tese (Doutorado em Ciências Sociais), Unicamp, Campinas, 2011.

FRAISSE, Geneviève. Droit naturel et question de l'origine dans la pensée féministe au XIXe siècle. In: Stratégies des femmes. Paris, Tierce, 1984, pp.375-390.

FRAISSE, Geneviève. Muse de la raison. La démocratie exclusive et la dif érence des sexes. Aix-en-Provence, Alinéa, 1989.

GALEANO, Eduardo. Memorias y desmemorias. Revista Brecha, vol. 592, $\mathrm{n}^{\circ} \quad 01, \quad$ Montevidéu, 1997 [http://www.galeon.com/froblesortega/memoriasydesmemorias.htm acesso em 09 nov. 2018].

GALVÃO, Karla. Encontros do feminismo; uma análise do campo feminista brasileiro a partir das esferas do movimento, do governo $e$ da academia. Tese (Doutorado em Ciências Humanas), Universidade Federal de Santa Catarina, Florianópolis, 2008.

GALVÃO, Karla; QuADROS, Marion. Feminismo e homens: Reflexões sobre participação, pesquisa e militância. In: Fazendo Gênero 9: Diásporas, Diversidades, Deslocamentos. Florianópolis, Universidade Federal de Santa Catarina, 2010.

HARNER, June. Emancipação do sexo feminino: A luta pelos direitos da mulher no Brasil. 1870 - 1940. Florianópolis, Mulheres, 2003.

HERNANDÉZ, Franklin Gil. Para [qué estudiar a] hombres? Hombres, feminismo y estúdios sobre masculinidades. In: III Colóquio Internacional de Estudios Sobre Varones y Masculinidades. Medelin, 2008

[http://www.redmasculinidades.com/resource/images/BookCatalog/Do c/00081.pdf - acesso em 29 julho 2012].

Homens em ação. Mulherio. São Paulo, ano 1, n¹, jun. 1981, pp.4.

KAUFMAN, Michael. Los hombres, el feminismo y las experiências contradictorias del poder entre los hombres, 1994 [http:.//www.michaelkaufman.com/wp-content/uploads/2008 - acesso em 29 ago. 2012]. 
LEITE, Rosalinda S. C. Brasil Mulher e Nós Mulheres: origens da imprensa feminista brasileira. Cadernos de Crítica Feminista, CFH/CCE/UFSC, vol. 11, 2003, pp.234-321.

MATIAS, Daniel Felipe Mendes. Narrativas de homens feministas portugueses. Dissertação (Mestrado em Psicologia Comunitária), Instituto Superior de Psicologia Aplicada, Lisboa, 2008.

MEDRADO, Benedito; LYRA, Jorge. Por uma matriz feminista de gênero para os estudos sobre homens e masculinidades. Revista Estudos Feministas, vol. 16, n³, Florianópolis, 2008, pp.809-840.

MercadAnte, Aloísio. Ser macho é cinza. Mulherio, São Paulo, ano 2, no7, ago. 1982, pp.3.

NiCHOLSON, Linda. Interpretando o gênero. Revista Estudos Feministas, vol. 8, n² 2, Florianópolis, 2000, pp.8-41.

PrADO, Danda. Mulherio, São Paulo, ano 2, n¹0, dez. 1982, pp.3.

PRECIADO, Paul Beatriz. Féminisme amnésique. Jornal Libération on-line, mai, 2014 [http://www.liberation.fr/societe/2014/05/09/feminismeamnesique_1014052 - acesso em 23 set. 2015].

RAGO, Margareth. Os feminismos no Brasil: dos "anos de chumbo" à era global. Revista Estudos Feministas, n³, vol. 2, Florianópolis, 2003, pp.36-50.

SARTI, Cintia. Feminismo no Brasil: Uma trajetória particular. Cadernos de Pesquisa, n64, São Paulo, 1988, pp.38-47.

SARTI, Cintia. O feminismo brasileiro desde os anos 1970: revisitando uma trajetória. Revista Estudos Feministas, vol.12, n² 2, Florianópolis, 2004, pp.35-50.

STOLKE, V. La mujer es puro cuento: La cultura del genero. Revista Estudos Feministas, vol.12, n² 2, Florianópolis, ago.2004, p.77-105.

TELES, Lúcio. Qual é a cor do machismo. Mulherio, ano 2, n9 9 , São Paulo, out. 1982, pp.2.

TEles, Maria Amélia. de Almeida. Breve história do feminismo no Brasil. São Paulo, Brasiliense, 1993. 